\title{
Neonatal near misses and associated factors among mother's who give a live neonate at Hawassa City governmental hospitals, 2019: a facility based cross- sectional study design
}

\author{
Anteneh Fikrie Tekola ${ }^{1,2^{*}}$, Genet Baye ${ }^{3}$, Elias Amaje ${ }^{2}$ and Kebede Tefera ${ }^{4}$
}

\begin{abstract}
Background: Neonatal near miss is a neonate who nearly died but survived from a severe complication occurred during pregnancy, birth or within 0-28 days of extra-uterine life. However, there is no available data that quantifies the magnitude of neonatal near miss (NNM) in Ethiopia where there is high prevalence of neonatal mortality. Therefore, this study is designed to provide information about the magnitude and associated factors of neonatal near miss among women who give a live birth at Hawassa City Governmental hospitals, 2019.

Methods: A facility based cross-sectional study design was conducted on 604 mothers who gave live neonates at Adare General Hospital and Hawassa University Comprehensive and Specialized Hospital from May 9, 2019 to June 7, 2019. Face to face interviewer administered structured questionnaire with a supplementation of maternal and neonatal medical records with checklists were used to collect the data. Data were coded and entered in to Epi data version 3.1 and then exported to the Statistical Package for Social Science IBM version 25 for analysis. Descriptive statistics was run and the data were presented using frequency tables and figure. The bi-variable and multivariable logistic regression was used to identify the possible factors of neonatal near miss. Finally, Adjusted Odds Ratio and 95\% Confidence Intervals were used to declare statsticall significance.
\end{abstract}

Result: Among all 604 selected live births an overall proportion of NNM cases, 202 (33.4\%) (95\% Cl: 29.7-37.1\%) was obtained at Hawassa City Government Hospitals. Respiratory distress 158 (94\%) and infection or sepsis 138 (84\%) were found to be the leading causes of NNM cases in our study. Governmental and non-governmental employed mother (AOR =3.05, 95\% Cl: 1.46-6.44) and Cesarean Section delivery (AOR=1.89, (95\% Cl: 1.25-2.83)) were positively significantly associated with neonatal near miss. Whereas, pregnancy induced Hypertension (AOR $=0.43$, 95\%Cl: 0.27-0.69) was negatively associated with neonatal near miss.

\footnotetext{
* Correspondence: antenehfikrie3@gmail.com

'Public Health Departement, Pharma College Hawassa Campus, Hawassa, Ethiopia

${ }^{2}$ College of Medical and Health Sciences, School of Public Health, Bule Hora University, Bule Hora, Ethiopia

Full list of author information is available at the end of the article
}

(c) The Author(s). 2021 Open Access This article is licensed under a Creative Commons Attribution 4.0 International License, which permits use, sharing, adaptation, distribution and reproduction in any medium or format, as long as you give appropriate credit to the original author(s) and the source, provide a link to the Creative Commons licence, and indicate if changes were made. The images or other third party material in this article are included in the article's Creative Commons licence, unless indicated otherwise in a credit line to the material. If material is not included in the article's Creative Commons licence and your intended use is not permitted by statutory regulation or exceeds the permitted use, you will need to obtain permission directly from the copyright holder. To view a copy of this licence, visit http://creativecommons.org/licenses/by/4.0/. The Creative Commons Public Domain Dedication waiver (http://creativecommons.org/publicdomain/zero/1.0/) applies to the data made available in this article, unless otherwise stated in a credit line to the data. 
(Continued from previous page)

Conclusion: This study revealed relatively high prevalence of NNM in the study areas. Employed women, pregnancy induced hypertension and cesarean section mode of delivery were found to be independent factors affecting the prevalence of NNM cases. Therefore, HUCSH and Adare general Hospitals should focus on proving quality antenatal care and prevention of occupational related problems among pregnant women.

Keywords: Live neonates, Neonatal near miss, Governmental hospital, Hawassa City

\section{Background}

Globally in 2017, 2.5 million babies died from preventable causes like prematurity, complication during the time of birth, bacterial infections, congenital malformations, and poor quality or no health care given at all. Almost all neonatal deaths (98\%) occur in low- and middle-income countries, with a highest proportion of $78 \%$ in Southern Asia and sub-Saharan Africa. Eight of the 10 countries with the highest NMRs are in Africa [1, 2]. Neonatal mortality is still high in developing countries even if it is possible to minimize worldwide. It is estimated that the number of NNM is two to eight times higher than the number of neonatal deaths [3-5].

Ethiopia has achieved under-five mortality reduction Millennium Development Goal (MDG) targets [6]. However, both infant and neonatal mortality still remains a top priority plan of the national government because neonatal mortality rate shares the highest proportion $44 \%$ of under five deaths [7]. Neonatal mortality becomes continuous challenge for Ethiopia rolling from MDG to Sustainable Development Goal (SDG). The SDG target to end preventable neonatal deaths obliges all countries to reduce the neonatal mortality rate to $12 / 1000$ live births by $2030[1,8]$.

According to Ethiopian Demographic and Health Survey (EDHS) 16 years report from 2000 to 2016, a steady declined infant, child and under-five mortalities were observed. Similarly, a 2016 EDHS report revealed a neonatal mortality rate of 29/1000 Live Birth (LB), meaning that 1 in every 35 neonates dies within the first month of their life [7]. Surprisingly, the 2019 mini EDHS report revealed an increased neonatal mortality, 30/1000LB, which is higher than prior report [9]. Different literatures show that NNM is a condition where newborns develop complication leading to nearly death condition but then survived in the first 28 days of life even though there is still no standard definition to classify NNM. Regardless of any criteria's, neonatal deaths use as the gold standard [10, 11]. Thus, the best option to detect NNM cases in hospitals are intensive care units (ICUs) and neonatal ICUs combined with the pragmatic and management criteria [12]. Therefore, for this study, NNM criterions were adapted from World Health Organization (WHO) pragmatic and management criteria [11], Newborn Services Clinical Guideline, 2019 [2] and Ethiopian NICU guideline [13].

The main causes of neonatal death worldwide are complications arising from preterm birth, asphyxia during labor and sepsis, corresponding to $75 \%$ of these deaths. Majority of neonatal deaths are preventable and to reduce these deaths; invest in maternal and neonatal care during childbirth and in the first $24 \mathrm{~h}$ after birth $[1,2]$. Severe infection, LBW and birth asphyxia were the most common causes of NNM in the health facilities [2, 14-16]. Similarly, in Ethiopia, 2015 government report revealed that Preterm birth complications 22\%, intra-partum related events 32\%, infection $20 \%$ and congenital abnormalities $12 \%$ were among the leading causes of neonatal death $[2,17,18]$.

Adherence to essential newborn care would benefit newborns, adding special and intensive care services would reduce neonatal mortality by $50 \%$ [13]. Research conducted in Benchi Maji Zone revealed 22.8\% of death among neonates who were admitted in NICU [19]. Identification and correction of factors that may improve maternal and neonatal care are more likely to contribute to the reduction in neonatal mortality rate [4]. Only few researches were conducted on neonatal near miss, even those studies that were conducted so far were unable to quantify the NNM cases in terms of its magnitude. Moreover, in the study setting there is no available data that quantifies the magnitude and factors associated with neonatal near miss.

Therefore, this study is intended to fill the gabs of those studies and to provide concrete information about the magnitude and associated factors of NNM in Hawassa City Governmental Hospitals.

\section{Methods}

\section{Study setting, design and period}

This hospital based cross-sectional study was conducted at Hawassa University Comprehensive Specialized Hospital (HU-CSH) and Adare General Hospitals which are both found at Hawassa City, Southern Ethiopia. Hawassa City is the capital city of southern nation's nationalities and people's region (SNNPR) from May 9, 2019 to June 7, 2019. HU$\mathrm{CSH}$ is a teaching hospital for medicine and health sciences students. It has more than 350 beds, of which 84 are reserved for maternity beds, and perform more than 4378 deliveries per year. Likewise, Adare General Hospital has more than 
126 beds, of which around 18 are used for maternity beds, and perform over 4238 deliveries per year. Both Hospitals are used as a referral where most complicated cases from the southern region and neighbor region zones served. Additionally, the city health centers are also referred the complicated cases to Adare General Hospital. These two hospitals are the only one giving ICU service for neonates at Zonal level for the catchment area.

\section{Study participants, inclusion and exclusion criteria}

All live births during the data collection period at the selected Hospitals were included in the study, whereas multiple pregnancies, neonatal deaths, and neonates who were referred from other health care institutions that were out of the study hospitals were excluded.

\section{Sample size determination and sampling procedure}

Sample size for first objective, assessing Neonatal Near Misses (NNM) was calculated using single population proportion formula. The specifications made during the computation were: Prevalence of NNM 36.7\% [17], 95\% confidence level, $4 \%$ margin of error and $10 \%$ compensation for possible missing values. The ultimate sample size was calculated as 614. Sample size for second objective was computed by Epi info7 Statcalc version 7.1.4.0 software by the assumptions of, 95\% level of confidence, power of $80 \%$, the ratio of exposed to unexposed 1:1 and percent of outcome in unexposed group 15.9 and AOR of 2. The percent of outcome in unexposed group and AOR were taken from the study conducted in Southern Ethiopia; the determinate variable was premature rupture of membrane [17]. By substituting the above values in to software the estimated sample size was 432 . By comparing the two sample size calculated, the first sample size was larger than the second as a result we took 614 as the final calculated sample size for the study. Subsequently, the calculated sample size was allocated for both hospitals proportionally based on their prior annual delivery report. Subsequently, due to the rare cases of NNM, all the consecutive live births were included in the study during the study period.

\section{Data collection and quality assurance}

Data were collected by a face-to-face-interviewer administered structured questionnaire and standard data extractions checklist from medical record were used to collect the data. The standard data extraction was prepared by reviewing prior literatures $[12,16,20]$ and WHO recommended information [11]. As there are different languages in the study area, Hawassa City, the questionnaire was primarily prepared in English and translated to the regional working language, Amharic, during the interview (additional file 1). Four diploma nurses and two Degree holder Nurses were recruited as the data collectors and supervisors respectively. All questions in the questionnaire were clarified to each data collectors before the data collection period. Likewise, the data collectors were trained on how to ask questions exactly as stated in the questionnaire and provide only nondirective guidance. Following to three days training, data collectors started the data collection. To reduce information bias the questionnaire was pretested on Bushulo Maternity Health Center prior to the actual data collection period. Primary data, socio-demographic and economic characteristics of mothers, were collected through face-toface-interview and secondary data, obstetrics and medical history of mothers and neonatal characteristics, were extracted from maternal and neonate medical records by standard checklist.

Neonates who sustained NNM cases were identified by well trained and experienced data collectors using the standard WHO recommended pragmatic or management severity criteria's (Table 1 ). Independent variables were: Socio-economic and demographic characteristics (Age, income, Household size, maternal and paternal educational status, place of residence, maternal occupational status, marital status), maternal obstetric history (ANC, frequency of ANC, parity, gravidity, gestational age at first ANC visit, abortion history, Premature Rupture of Membrane, Mode of delivery) and maternal medical history (Diabetic mellitus, Pregnancy induced diabetic mellitus, Anemia, Hypertension, Pregnancy induced hypertension, syphilis).

\section{Data processing and analysis}

Data were checked for completeness and consistencies, coded and entered into Epi data version 3.1 then exported to Statistical Package for Social Science (SPSS) version 25 for analysis. Continuous variable, maternal age was summarized by median with IQR because the data were not normally distributed and presented using frequency tables, figures and charts. The bi-variable and multivariable logistic regression

Table 1 Criteria to identify neonatal near-miss cases. This Table shows the criteria to identify neonatal near-miss cases in HU-CSH and Adare General Hospitals, Hawassa City, Southern Ethiopia, 2019

\begin{tabular}{ll}
\hline Criteria & Descriptions \\
\hline Pragmatic criteria & Birth weight less than 1750 g, Gestational Age less than 33 weeks and Apgar score less than 7 at 5 min [11, 21] \\
$\begin{array}{l}\text { Management severity } \\
\text { criteria }\end{array}$ & $\begin{array}{l}\text { Respiratory distress, blood transfusion, presence of infection with clinical concern, Bile stained vomiting, feeding problems } \\
\text { severe enough to cause clinical concern, Cardiopulmonary resuscitation, Congenital Malformations, Convulsion, Surgery, } \\
\end{array}$ \\
\hline
\end{tabular}


was used to identify the possible factors of neonatal near miss at Hawassa city governmental hospitals. A variable with $p$ value $\leq 0.2$ during bivariate analysis was entered in to multivariable logistic regression for further analysis so as to control the confounding variables. Multi co-linearity was checked by collinearity statistics (Variance inflation factor). Finally, Adjusted Odds Ratio (AOR) and 95\% Confidence Intervals (CIs) were used to declare statstical significance.

\section{Results}

\section{Socio-demographic characteristics of respondents}

During the study period, a total of 724 live births attended in both study hospitals. Of these, 604 records were met the eligibility criteria and included in this study and made the response rate of $98.3 \%$. Whereas, of which the eligibility of $10(1.7 \%)$ could not be included because of incomplete maternal data records at least with one variable. The median $( \pm \mathrm{IQR})$ age of the respondents was $26( \pm 7)$ years with a minimum and maximum age of 15 and 49 years respectively. Majority of the respondents 364 (60.3\%) fall in the 25-34 years' age group. The vast majority of neonate's mothers 568 (94\%) were married. Regarding the occupational status of respondents more than half of respondents, 317 (52.5\%) were housewives. Out of the total respondents, 88 (14.6\%) of the study participants had monthly income of less than 43 USD. Pertaining to educational status of the respondents, $86(14.2 \%)$ never attended any type of formal education (Table 2).

\section{Maternal obstetrics and chronic disease history characteristics}

Of all the neonates' mother, $548(90.7 \%)$ had at least one ANC follow up during their current pregnancy. On the other hand, almost half, 291 (48.2\%) of the respondents had less than four ANC visits in their current pregnancy. More than two third, 420 (69.5\%) of respondents were multigravida. Regarding the parity, 250 (41.4\%) of the respondents were multiparous. One in seven, 89 (14.7\%) and one in ten, $59(9.8 \%)$ respondents had history of abortion and neonatal deaths respectively. Regarding the mode of delivery, the majority 397 (65.7\%) gave birth by vaginal deliveries. More than half of respondents, 340 (56.3\%) had premature rupture of membrane.

Regarding chronic diseases history of respondents, 99 (16.4\%), 11 (1.8\%) and 7 (1.2\%) had pregnancy induced hypertension, Chronic Diabetes mellitus and pregnancy induced diabetic mellitus during the current pregnancy respectively. Similarly, among all neonates' mothers, 13 (2.2\%) had diagnosed with syphilis during the current pregnancy. The vast majority, 553 (91.6\%) of the respondents had vaginal bleeding (Table 3).
Table 2 Socio-demographic characteristics of mothers. This table indicates the socio-demographic characteristics of mothers who gave live birth in Hawassa City Governmental Hospitals, Southern Ethiopia, 2019 $(n=604)$

\begin{tabular}{|c|c|c|}
\hline Characteristics & Frequency & Percent (\%) \\
\hline \multicolumn{3}{|l|}{ Age in years } \\
\hline $15-24$ & 191 & 31.6 \\
\hline $25-34$ & 364 & 60.3 \\
\hline$\geq 35$ & 49 & 8.1 \\
\hline \multicolumn{3}{|l|}{ Marital status } \\
\hline Married & 568 & 94 \\
\hline Others* & 36 & 4 \\
\hline \multicolumn{3}{|l|}{ Place of residence } \\
\hline Urban & 437 & 72.4 \\
\hline Rural & 167 & 27.6 \\
\hline \multicolumn{3}{|l|}{ Occupation } \\
\hline House wife & 317 & 52.5 \\
\hline Employed & 144 & 23.8 \\
\hline Merchant & 42 & 7.0 \\
\hline Others $^{\#}$ & 101 & 16.7 \\
\hline \multicolumn{3}{|l|}{ Maternal Education } \\
\hline Illiterate & 86 & 14.2 \\
\hline Primary education & 195 & 32.3 \\
\hline Secondary education & 161 & 26.7 \\
\hline College and above & 162 & 26.8 \\
\hline \multicolumn{3}{|l|}{ Father's Education } \\
\hline Illiterate & 47 & 7.8 \\
\hline Primary education & 127 & 21.0 \\
\hline Secondary education & 171 & 28.3 \\
\hline College and above & 259 & 42.9 \\
\hline \multicolumn{3}{|l|}{ House hold family size } \\
\hline$<4$ & 331 & 54.8 \\
\hline $4-7$ & 213 & 35.3 \\
\hline$>7$ & 60 & 9.9 \\
\hline
\end{tabular}

*single, divorced "farmers, students, daily labors

\section{Neonatal near miss}

Among all 604 selected live births an overall proportion of NNM cases, 202 (33.4\%; 95\% CI: 29.7-37.1\%) was observed. In this study the majority of neonates were tackled by respiratory distress, 158 (78.2\%) followed by sepsis 138 (68.3\%). Seven (3.46\%) of NNM cases were admitted due to the need of blood transfusion (Table 4).

\section{Factors associated with NNM}

After adjusting or controlling the potential confounding variables by the multivariate analysis: Employed mothers $[\mathrm{AOR}=3.05(95 \% \mathrm{CI}: 1.46-6.44)]$, pregnancy induced $\mathrm{HTN} \quad[\mathrm{AOR}=0.42(95 \% \mathrm{CI}: 0.26-0.66)]$ and cesarean 
Table 3 Obstetric and chronic disease characteristics of mothers This table shows the obstetric and chronic disease characteristics of mothers at Hawassa City Government Hospitals, Southern, Ethiopia, $2019(n=604)$

\begin{tabular}{|c|c|c|}
\hline Variable $(n=604)$ & Frequency & Percent (\%) \\
\hline \multicolumn{3}{|l|}{ ANC } \\
\hline Yes & 548 & 90.7 \\
\hline No & 56 & 9.3 \\
\hline \multicolumn{3}{|l|}{ Parity } \\
\hline Nulliparous & 182 & 30.1 \\
\hline Primiparous & 172 & 28.5 \\
\hline Multiparous & 250 & 41.4 \\
\hline \multicolumn{3}{|l|}{ History of abortion } \\
\hline Yes & 89 & 14.7 \\
\hline No & 515 & 85.3 \\
\hline \multicolumn{3}{|l|}{ Number ANC $(n=548)$} \\
\hline$<4$ & 291 & 48.2 \\
\hline$>=4$ & 257 & 42.5 \\
\hline \multicolumn{3}{|c|}{ Gestation at first visit $(n=548)$} \\
\hline First trimester & 173 & 28.6 \\
\hline Second trimester & 338 & 56 \\
\hline Third trimester & 37 & 6.1 \\
\hline \multicolumn{3}{|c|}{ Premature rupture of membrane } \\
\hline Yes & 340 & 56.3 \\
\hline No & 264 & 43.7 \\
\hline \multicolumn{3}{|l|}{ Mode of delivery } \\
\hline Vaginal deliveries* & 397 & 65.7 \\
\hline Cesarean section & 207 & 34.3 \\
\hline \multicolumn{3}{|c|}{ Pregnancy induced hypertension } \\
\hline Yes & 99 & 16.4 \\
\hline No & 505 & 83.6 \\
\hline \multicolumn{3}{|l|}{ Diabetic mellitus } \\
\hline Yes & 11 & 1.8 \\
\hline No & 593 & 98.2 \\
\hline \multicolumn{3}{|l|}{ Hypertension } \\
\hline Yes & 46 & 7.6 \\
\hline No & 558 & 92.4 \\
\hline \multicolumn{3}{|c|}{ Pregnancy induced diabetic mellitus } \\
\hline Yes & 7 & 1.2 \\
\hline No & 597 & 98.2 \\
\hline \multicolumn{3}{|l|}{ Syphilis } \\
\hline Yes & 13 & 2.2 \\
\hline No & 591 & 97.8 \\
\hline \multicolumn{3}{|l|}{ Vaginal bleeding } \\
\hline Yes & 553 & 91.6 \\
\hline No & 51 & 8.4 \\
\hline
\end{tabular}

mode of delivery $[\mathrm{AOR}=1.89(95 \%$ CI:1.25-2.83)] were significantly associated with NNM cases. Accordingly, the odds of NNM were three fold among neonates whose mothers occupational status is employed as compared to their counterparts (AOR $=3.05,95 \%$ CI: $1.46-$ 6.44). A mother who had pregnancy induced HTN was $58 \%$ times less likely to have NNM neonate as compared to mothers hadn't (AOR $=0.42,95 \% \mathrm{CI}$ : $0.26-0.66$ ). A neonate's mother who gave birth by cesarean mode of delivery were nearly 1.9 times more likely to have NNM cases compared to mothers who gave birth through vaginal deliveries (AOR $=1.89,95 \%$ CI:1.25-2.83) (Table 5).

\section{Discussion}

Among all 604 selected live births an overall proportion of NNM cases, 202 (33.4\%) [95\% CI: 29.7-37.1\%] was obtained at Hawassa City Government Hospitals. These NNM cases were identified using pragmatic or management criteria's alone or combined. Occupational status of mothers, Pregnancy induced Hypertension and mode of delivery were found to be independent predictors of factors affecting the prevalence of NNM cases among mothers who gave live neonates at Hawassa City Governmental Hospitals.

The finding of this study revealed that NNM cases of $33.4 \%$, which is ten times higher than the national neonatal death rate [9]. The result of this study is in line with similar other study conducted in Northeastern Brazil [12] and Uganda [16]. However, the finding of this study was inconsistent with similar studies conducted worldwide: low and middle income countries in Africa [20] and three similar studies in Brazil [3, 5, 14]. The observed high prevalence in this study might be due to the referral nature of the health institutions where an increased probability of attending more complicated cases from the catchment area and neighboring region. Moreover, the hospital delivery rate, which is 50\% [9], in Ethiopia, might be another contributing factor to the observed high rate in this study compared to other studies.

According to this study, cesarean section identified as a risk factor for NNM. Thus, the odds of NNM cases were 1.9 times higher among mothers who gave birth through cesarean section as compared to mothers who gave birth through vaginal deliveries $(\mathrm{AOR}=1.89$, $(95 \%$ CI:1.25-2.83)). This is result is corroborated by different studies conducted at national and global level $[3,4,10$, 17]. The possible reason for this is that cesarean section delivery has increased Neonatal morbidity and mortality and also result in slow or no improvement of neonatal outcomes [22]. Also, cesarean section delivered newborns had less skin-to-skin contact with their mothers immediately after delivery and makes the neonates unable to breastfeeding within one hour of birth in turn put the neonate at greater risk of early 
Table 4 Prevalence of NNM cases based on pragmatic and management criteria's. This table indicates the prevalence of NNM cases based on pragmatic and management criteria's at Hawassa City Government Hospitals, Southern Ethiopia, 2019 ( $n=202)$

\begin{tabular}{|c|c|c|c|}
\hline \multirow[t]{2}{*}{ Criteria's } & & \multicolumn{2}{|c|}{ Neonatal Near Miss cases } \\
\hline & & Number & Percent (\%) \\
\hline \multirow[t]{3}{*}{ Pragmatic criteria's } & Birth weight $<1750$ & 11 & 5.44 \\
\hline & Gestational age $<33$ weeks & 24 & 11.88 \\
\hline & APGAR $^{*}$ score $<7$ at 5 th minute & 56 & 27.72 \\
\hline \multirow[t]{12}{*}{ Management criteria's } & Respiratory distress & 158 & 78.21 \\
\hline & Infection & 138 & 68.31 \\
\hline & Parenteral nutrition & 170 & 84.15 \\
\hline & Blood transfusion & 7 & 3.46 \\
\hline & Bile stained vomiting & 14 & 6.93 \\
\hline & Feeding problems & 82 & 40.59 \\
\hline & Cardiovascular Problems & 14 & 6.93 \\
\hline & Congenital Malformations & 17 & 8.41 \\
\hline & Convulsion & 9 & 4.45 \\
\hline & Surgery & 11 & 5.44 \\
\hline & Phototherapy within $24 \mathrm{~h}$ of life & 53 & 26.23 \\
\hline & Any intubation & 83 & 41.09 \\
\hline
\end{tabular}

"APGAR: Appearance, Pulse, Grimace, Activity, and Respiration

complications [23]. Likewise cesarean section on demand sometimes could be a risk factor for prematurity, which is one of the components of pragramatic criteria. However, the cesarean section delivery by itself could not be responsible for adverse neonatal outcomes. Rather the occurrences of maternal and fetal complications which would lead to indication of cesarean section could actually be responsible for the incident of neonatal near miss. Therefore, cesarean section should be undertaken merely owing to medical indication.

The current study shows that neonate's mothers who have pregnancy induced HTN had 58\% times reduced odds of experiencing neonatal near miss as compared to mothers who had no pregnancy induced hypertension ( $\mathrm{AOR}=0.42$, 95\% CI: $0.26-0.66)$. This result is corroborated by a study conducted at Brazil [24]. This congruency might be due to the fact that women with gestational hypertension are more likely to have higher rates of CS delivery so as to prevent neonatal complications leading to NNM cases early. There is also scientific evidence about the importance of use of CS during delivery among women with pregnancy induced hypertension [25]. However, this study result is incongruent with a study conducted in Southern Ethiopia [17], the reason might be methodological (study area, sample size and study design) difference.

There is published evidence for the adverse effects of occupational stress on fetal growth and development [26]. This study also revealed that the odds of NNM cases were three times higher among employed mothers than unemployed mothers $(\mathrm{AOR}=3.05$, 95\% CI: $1.46-$ 6.44). This finding is consistent with other previous studies conducted in abroad [26-28]. This is due to the fact that women who are engaged in hard physical work are at most risk to have adverse pregnancy outcomes [29]. Furthermore, women who are working in unfavorable environments such as; stress, prolonged standing and sitting, and contact with different chemicals could expose her to have a preterm birth and neonatal abnormalities, which are the predominant causes of NNM [28].

This study has added weight to the existing literature by quantifying the NNM cases and might be used as an input for health policymakers and program developers particularly working on neonatal health in the health care delivery system. However, the findings from this study would be difficult to extrapolate to the wider population, because the study was hospital based, but not community based. Data were only collected at appoint in time from mothers who gave live newborns at the hospitals and, therefore, cases referring from the community may have been missed. The prevalence of NNM might be higher because HUCSH is tertiary type of hospital and Adare general hospital is also a referral option for all government and private health facilities for Hawassa city, Sidama and neighborhoods zones this might increase the possibility of attending more complicated cases resulting over estimation of the magnitude. Moreover, the data were collected with the supplementation of medical records, which were incomplete of some variables 
Table 5 Factors associated with neonatal near miss. This table shows factors associated with neonatal near miss among mothers giving live births at Hawassa City government Hospitals, Southern, Ethiopia, $2019(n=604)$

\begin{tabular}{|c|c|c|c|c|}
\hline \multirow[t]{2}{*}{ Variable } & \multicolumn{2}{|c|}{ Neonatal Near miss } & \multirow[t]{2}{*}{ COR $(95 \% \mathrm{Cl})$} & \multirow[t]{2}{*}{ AOR $(95 \% \mathrm{Cl})$} \\
\hline & Yes N (\%) & No $N(\%)$ & & \\
\hline \multicolumn{5}{|l|}{ Age in years } \\
\hline $15-24$ & $65(32.2)$ & $126(31.3)$ & 1 & \\
\hline $25-34$ & $120(59.4)$ & $244(60.7)$ & $1.04(0.72-1.51)$ & \\
\hline$\geq 35$ & $17(8.4)$ & $32(8)$ & $0.97(0.50-1.87)$ & \\
\hline \multicolumn{5}{|l|}{ Marital status } \\
\hline Married & $190(94.1)$ & $378(94)$ & $0.99(0.48-2.03)$ & \\
\hline Others ${ }^{\&}$ & $12(5.9)$ & $24(6)$ & 1 & \\
\hline \multicolumn{5}{|l|}{ Maternal Education } \\
\hline Illiterate & $42(20.8)$ & $44(10.9)$ & $0.42(0.25-0.73)$ & $0.65(0.30-1.41)$ \\
\hline Primary education & $68(33.7)$ & $127(31.6)$ & $0.76(0.48-1.19)$ & $1.39(0.72-2.69)$ \\
\hline Secondary education & $45(22.3)$ & $116(28.9)$ & $1.05(0.65-1.71)$ & $1.68(0.89-3.17)$ \\
\hline College and above & $47(23.3)$ & $115(28.6)$ & 1 & 1 \\
\hline \multicolumn{5}{|l|}{ Occupational status of mothers } \\
\hline House wife & $117(57.9)$ & $200(49.8)$ & $1.16(0.73-1.84)$ & $1.56(0.92-2.63)$ \\
\hline Employed (Gov't, NGO \& Private) & $33(16.3)$ & $111(27.6)$ & $2.29(1.31-4.00)$ & $3.05(1.46-6.34)^{*}$ \\
\hline Merchant & $11(5.4)$ & $31(7.7)$ & $1.92(0.87-4.26)$ & $2.26(0.95-5.35)$ \\
\hline Others ${ }^{\#}$ & $41(20.4)$ & $60(14.9)$ & 1 & 1 \\
\hline \multicolumn{5}{|l|}{ Father's Education } \\
\hline Illiterate & $17(8.4)$ & $30(7.5)$ & 1 & \\
\hline Primary education & $57(28.2)$ & $70(17.4)$ & $0.69(0.43-1.38)$ & \\
\hline Secondary education & $51(25.2)$ & $120(29.9)$ & $1.33(0.67-2.63)$ & \\
\hline College and above & 77 (38.1) & $182(45.3)$ & $1.33(0.69-2.57)$ & \\
\hline \multicolumn{5}{|l|}{ House hold family size } \\
\hline$<4$ & $110(54.5)$ & $221(55)$ & 1 & 1 \\
\hline $4-7$ & $66(32.7)$ & $147(36.6)$ & $1.10(0.76-1.60)$ & $1.27(0.85-1.90)$ \\
\hline$\geq 7$ & $26(12.9)$ & $34(8.9)$ & $0.65(0.37-1.13)$ & $0.97(0.51-1.85)$ \\
\hline \multicolumn{5}{|l|}{ Residence } \\
\hline Urban & $147(72.8)$ & $290(72.1)$ & 1 & \\
\hline Rural & $55(27.2)$ & $112(27.9)$ & $1.03(0.70-1.50)$ & \\
\hline \multicolumn{5}{|l|}{ ANC Visit } \\
\hline Yes & $182(90.1)$ & $366(91)$ & 1 & \\
\hline No & $20(35.7)$ & $36(64.3)$ & $0.89(0.50-1.59)$ & \\
\hline \multicolumn{5}{|l|}{ Number of ANC } \\
\hline No visit & $20(9.9)$ & $36(9)$ & 1 & 1 \\
\hline $1-3$ & $111(55)$ & $180(44.88)$ & $0.90(0.49-0.164)$ & $0.63(0.31-1.27)$ \\
\hline$\geq 4$ & $71(35.1)$ & $186(46.12)$ & $1.44(0.78-2.66)$ & $1.02(0.48-2.16)$ \\
\hline \multicolumn{5}{|l|}{ Vaginal bleeding } \\
\hline Yes & $181(89.6)$ & $372(92.5)$ & $1.44(0.80-2.58)$ & $1.46(0.77-2.76)$ \\
\hline No & $21(10.4)$ & $30(7.5)$ & 1 & 1 \\
\hline \multicolumn{5}{|l|}{ Mode of delivery } \\
\hline Vaginal & $113(55.9)$ & $284(70.6)$ & 1 & 1 \\
\hline Cesarean section & $89(44.1)$ & 118 (29.4) & $1.90(1.33-2.69)$ & $1.89(1.25-2.83)^{* *}$ \\
\hline
\end{tabular}


Table 5 Factors associated with neonatal near miss. This table shows factors associated with neonatal near miss among mothers giving live births at Hawassa City government Hospitals, Southern, Ethiopia, 2019 ( $n=604)$ (Continued)

\begin{tabular}{|c|c|c|c|c|}
\hline \multirow[t]{2}{*}{ Variable } & \multicolumn{2}{|c|}{ Neonatal Near miss } & \multirow[t]{2}{*}{ COR $(95 \% \mathrm{Cl})$} & \multirow[t]{2}{*}{ AOR $(95 \% \mathrm{Cl})$} \\
\hline & Yes N (\%) & No N (\%) & & \\
\hline \multicolumn{5}{|l|}{ Parity } \\
\hline Nulliparous & $65(32.2)$ & $117(29.1)$ & $0.97(0.65-1.45)$ & \\
\hline Primiparous & $49(24.3)$ & $123(30.6)$ & $1.36(0.89-2.00)$ & \\
\hline Multiparous & $88(43.6)$ & $162(40.3)$ & 1 & \\
\hline \multicolumn{5}{|c|}{ Rupture of membrane } \\
\hline Yes & $103(51)$ & $237(59)$ & $1.38(0.98-1.94)$ & $1.19(0.78-1.81)$ \\
\hline No & $99(49)$ & $165(41)$ & 1 & 1 \\
\hline \multicolumn{5}{|l|}{ Hypertension } \\
\hline Yes & $17(8.4)$ & $29(7.2)$ & $0.84(0.45-157)$ & \\
\hline No & $185(91.6)$ & $373(92.8)$ & 1 & \\
\hline \multicolumn{5}{|c|}{ Pregnancy induced HTN } \\
\hline Yes & $52(25.7)$ & $47(11.7)$ & $0.38(0.24-0.59)$ & $0.42(0.26-0.66)^{* * *}$ \\
\hline No & $150(74.3)$ & $355(88.3)$ & 1 & 1 \\
\hline
\end{tabular}
divorced, widowed: "student, daily labors, and farmers

for NNM like neonatal weight and Apgar score, and as a result they were obliged to be excluded. The participants were recruited during only one month and unable to consider seasonality as a risk factor of neonatal mortality. A prospective longitudinal research should be conducted by incorporating the full 28-days of the postnatal period.

\section{Conclusions}

In this study a higher prevalence of NNM cases was obtained at Hawassa City Government Hospitals. Cesarean Section delivery, employed mother and pregnancy induced hypertensions were significantly associated with NNM in this study. Respiratory distress and sepsis were also identified as the leading causes of NNM cases. Focused antenatal care should be strengthened so as to prevent the complications early. Likewise, an emphasis should also be given to pregnant women who are employed to government or private organizations to make sure that they are free from occupational related problems. The STROBE guideline was used to ensure the reporting of this cross-sectional study (Additional file 2).

\section{Supplementary Information}

The online version contains supplementary material available at https://doi. org/10.1186/s12884-021-03601-2.

Additional file 1. English version questionnaire.

Additional file 2. STROBE Checklist for reporting cross-sectional studies.

\section{Abbreviations}

ANC: Ante Natal Care; AOR: Adjusted Odds Ratio; Cl: Confidence Interval; COR: Crude Odds Ratio; CS: Cesarean Section; EDHS: Ethiopian Demographic and Health Survey; ICU: Intensive care unit; IQR: Inter Quartile Range; LB: Live Birth; LBW: Low Birth Weight; NICU: Neonatal Intensive Care Unit; NMR: Neonatal Mortality Rate; NNM: Neonatal Near Miss; SDGs: Sustainable Development Goals; WHO: World Health Organization

\section{Acknowledgements}

We would like to acknowledge Hawassa University Comprehensive Specialized Hospital and Adare General Hospital for permitting us to undertake this study. We are also grateful for Pharma College Hawassa Campus for the financial support of the study. Our thanks also go to data collectors, supervisors and those who were actively participated in our study.

\section{Authors' contributions}

AFT GBA conceptualized the paper, conducted the data collection process, and analyzed the data. AFT GBA wrote the draft of the manuscript. AF GBA, $E A, K T$ revised and edited the manuscript draft. All authors read and approved the final manuscript.

\section{Funding}

Pharma College has funded the research. The funding institution had no part in study design, information gathering, and analysis, judgment to publish, or development of the manuscript.

\section{Availability of data and materials}

Data essential for the conclusion are included in this manuscript. Additional data can be obtained from the corresponding author on a reasonable request.

\section{Ethics approval and consent to participate}

Ethical approval was obtained from the Institutional Review Board of Pharma College, School of graduate studies department of Public Health. Likewise, additional official letter of support was secured from both HUCSH and Adare General Hospital. All the participants were approached immediate to delivery by the data collectors and invited to participate in the study voluntarily and took informed verbal consent from each mother before data collection. The ethics committees had approved the verbal consent procedure. No parents/ guardians of the minors were included in this study. Moreover, information regarding any specific personal identifiers like name of the participants was not collected and also confidentiality of any personal information were also maintained. 


\section{Consent for publication}

Not applicable.

\section{Competing interests}

The authors declare that they have no competing interests.

\section{Author details}

'Public Health Departement, Pharma College Hawassa Campus, Hawassa, Ethiopia. ${ }^{2}$ College of Medical and Health Sciences, School of Public Health, Bule Hora University, Bule Hora, Ethiopia. ${ }^{3}$ Project Officer, Bushulo Child Development and Family Strengthening Project, SOS Child Village Hawassa Program, Hawassa, Ethiopia. ${ }^{4}$ College of Medicine and Health Sciences, School of Public Health, Hawassa University, Hawassa, Ethiopia.

Received: 9 September 2020 Accepted: 28 January 2021

Published online: 12 February 2021

\section{References}

1. Survive and thrive: transforming care for every small and sick newborn. Key findings. Geneva: World Health Organization; 2018 (WHO/FWC/MCA/18.11). Available from: https://apps.who.int/iris/bitstream/handle/10665/276655/ WHO-FWC-MCA-18.11-eng.pdf?ua=1, accessed 14 June 2020).

2. Healthy Newborn Network: Leading causes of neonatal deaths in Ethiopia 2015 [cited 2019 April, 20]. Available from: https://www. healthynewbornnework.org/country/ethiopia/

3. Silva GA, Rosa KA, Saguier ESF, Henning E, Mucha F, Franco SC. A populational based study on the prevalence of neonatal near miss in a city located in the south of Brazil: prevalence and associated factors. Rev Bras Saúde Matern Infant, Recife. 2017:17(1):159-67.

4. Santos JP, Pileggi-Castro C, J JSC, Silva AA, Duran P, Serruya SJ, et al. Neonatal near miss: a systematic review. BMC Pregnancy and Childbirth. 2015;15(320):1-10

5. Brasil DRPdA, Vilelaa MBR, Françaa KEXd, Sarinhoa SW. Neonatal Morbidity Near Miss in teritiary Hospitals in a capital of Northeast Brazil. Rev Paul Pediatr. 2019.

6. Assefa Y, Damme WV, Williams OD, Hill PS. Successes and challenges of the millennium development goals in Ethiopia: lessons for the sustainable development goals. BMJ Glob Health. 2017;2.

7. Ethiopia Demographic and Health Survey 2016: Key Indicators Report. Addis Ababa, Ethiopia, and Rockville, Maryland, USA.: Central Statistical Agency (CSA) [Ethiopia] and ICF, 2016.

8. Sustainable Development Goal 3: Ensure healthy lives and promote wellbeing for all at all ages: World health Organization; 2015. Available from: https://www.who.int/sdg/targets/en/s.

9. Ethiopia Mini Demographic and Health Survey 2019: Key Indicators. Rockville, Maryland, USA: EPHI and ICF.: Ethiopian Public Health Institute (EPHI) [Ethiopia] and ICF, 2019.

10. Avenant T. Neonatal near miss: a measure of the quality of obstetric care. Best Practice \& Research Clinical Obstetrics and Gynaecology. 2009:1-6.

11. Pileggi-Castro $C, J J C$, Perdon G, Mussi-Pinhata M, Cecatti J, Mori R, et al. Development of criteria for identifying neonatal near-miss cases: analysis of two WHO multicountry cross-sectional studies. BJOG. 2014;121(1):110-8.

12. THBd L, Katz L, Kassar SB, Amorim MM. Neonatal near miss determinants at a maternity hospital for high-risk pregnancy in Northeastern Brazil: a prospective study. BMC Pregnancy and Childbirth. 2018;18(401):1-8.

13. Worku B, Kidane L, Abera K, Kumar A, Egeli P, Kidolezi Y. Improving Neonatal Health Outcomes in Ethiopia through an innovative and Sustainable Health Care Model. Ethiop J Pediatr Child Health,. 2016;XIII (2).

14. Nardellol DM, Gurgelll| RQ GuimarãesI AMDAN, ERdO RIII, IDdC BII, CFL GI. Fetal and neonatal deaths of children of patients classified as near miss. Rev Bras Enferm [Internet]. 2017:70(1):98-105.

15. Mengesha HG, Wuneh AD, Lerebo WT, Tekle TH. Survival of neonates and predictors of their mortality in Tigray region, Northern Ethiopia: Prospective cohort study. BMC Pregnancy and Childbirth. 2016:16(202).

16. Nakimuli A, Mbalinda SN, Nabirye RC, Kakaire O, Nakubulwa S, Osinde MO, et al. Still births, neonatal deaths and neonatal near miss cases attributable to severe obstetric complications: a prospective cohort study in two referral hospitals in Uganda. BMC Pediatr. 2015:15(44):1-8.

17. Mersha A, Bante A, Shibiru S. Factors associated with neonatal near-miss in selected hospitals of Gamo and Gofa zones, southern Ethiopia: nested casecontrol study. BMC Pregnancy and Childbirth. 2019;19(516):1-8.
18. Nugussie F, Alemayehu M, Mariam KG. A case-control study examining determinants of neonatal near-miss in public hospitals in Tigray region, northern Ethiopia. Journal of Medical Science and Technology. 2018; 7(3):1-11.

19. Mekonnen T, Tenu T, Aklilu T, Abera T. Assessment of neonatal death and causes among admitted neonates in neonatal intensive care unit of Mizan Tepi University teaching hospital bench Maji zone, south-West Ethiopia, 2018. Clinics in Mother and Child Health. 2018;15(4):1-5.

20. Ronsmans C, Cresswell JA, Goufodji S, Agbla S, Ganaba R, Assarag B, et al. Characteristics of neonatal near miss in hospitals in Benin, Burkina Faso and Morocco in 2012-2013. Trop Med Int Health. 2016:21(4):535-45.

21. Santos JP, Cecatti JG, Serruya SJ, Almeida PV, Duran P. Mucio Bd, et al. neonatal near miss: the need for a standard definition and appropriate criteria and the rationale for a prospective surveillance system. Clinics. 2015; 70(12):820-6.

22. Mamta G, Vandana S. Caesarean section: mortality and morbidity. J Clin Diagn Res. 2018;12(9):06.

23. Pradol DS, Mendes RB, Gurge RQ, de ID BC, Cipolotti R, et al. The inflence of mode of delivery on neonatal and maternal short and longterm outcomes. Rev Saude Publica. 2018:52(95):1-11.

24. Kale PL, Mello-Jorge MHPd, Silva KSd, Fonseca SC. Neonatal near miss and mortality: factors associated with life-threatening conditions in newborns at six public maternity hospitals in Southeast Brazil. Cad Saúde Pública. 2017; 33(4).

25. Ahmed SS, Hosen MK, Lima LS, Sultana N, Abedin MF, Begum ML. Pregnancy Induced Hypertension and Associated Factors among Pregnant Women. Gynecology and Women's Health. 2017;3(4).

26. Mahmoodi Z, Mkarimlou SH, Dejman M, Vameghi M, Dolatia M, et al. Association of maternal working conditions with low birth weight: the social determinants of health approach. Ann Med Health Sci Res. 2015;5(6): 385-91.

27. Ohlsson A, Shah P, Economics loH. Determinants and Prevention of Low Birth Weight: A Synopsis of the Evidence. Alberta Perinatal Health Program. 2008

28. Bonzini M, Coggon D, Godfrey K, Inskip H, Crozier S, Palmer KT. Occupational physical activities, working hours and outcome of pregnancy: findings from the Southampton Women's survey. Occup Environ Med. 2009; 66:685-90.

29. I N, O'Mahony D, Daly S, Morrison J, Kellehera C. Occupational predictors of pregnancy outcomes in Irish working women in the Lifeways cohort. BJOG 7 April 2009:;16:943-52

\section{Publisher's Note}

Springer Nature remains neutral with regard to jurisdictional claims in published maps and institutional affiliations.

Ready to submit your research? Choose BMC and benefit from:

- fast, convenient online submission

- thorough peer review by experienced researchers in your field

- rapid publication on acceptance

- support for research data, including large and complex data types

- gold Open Access which fosters wider collaboration and increased citations

- maximum visibility for your research: over $100 \mathrm{M}$ website views per year

At BMC, research is always in progress.

Learn more biomedcentral.com/submissions 